\title{
A Manifesto for the Use of Video in Service Improvement and Staff Development in Residential Services for People with Learning Disabilities
}

\author{
W.M.L. Finlay ${ }^{1}$ \\ C. Antaki $^{2}$ \\ C. Walton ${ }^{3}$
}

1 Psychology Dept, University of Surrey, Guildford, Surrey GU2 7XH, w.finlay@surrey.ac.uk*

2 Dept of Social Sciences, Loughborough University, Loughborough LE11 3TU, c.antaki@Lboro.ac.uk

2 Dept of Psychology, Lancaster University, Lancaster LA1 4YF, c.walton@Lancaster.ac.uk

*Address for correspondence

Key words: intellectual disability, learning disability, mental retardation, developmental disabilities; empowerment; choice; control; disempowerment; staff; person-centred; video; service improvement; interaction; communication 
A manifesto

\title{
A Manifesto for the Use of Video in Service Improvement and Staff Development in Residential Services for People with Learning Disabilities
}

\begin{abstract}
In this paper we argue that video recording of actual practice should be a central tool for organisations attempting to improve services for people with learning disabilities. Since an important site for the disempowerment of service-users is in everyday, mundane interactions with service staff, an approach to staff development is needed which allows workers to see what they actually do and how they might do it differently. Research illustrates that retrospective self-reports of what people habitually do cannot capture much of the important details of communicative interaction. We argue that video recordings are the best way of doing this, and provide examples from our own work of the type of benefits that can arise. Finally, we set out a set of guidelines for the use of video recording in reflective practice in services.
\end{abstract}




\section{The Case}

Despite much flag-waving on the part of social services and NHS trusts in recent years, policy goals which stress the importance of promoting empowerment, independence and inclusion (Department of Health, 2001; HM Government, 2005) have only changed the ways in which services are delivered to a limited degree. Despite undoubted improvements in many areas, writers in the field of learning disabilities have noted the multitude of ways in which service structures, routines and attitudes stand in the way of empowerment and increasing independence (e.g. Beamer \& Brookes, 2001; Dowson, 1997; Edge, 2001; Harris, 2003; Jenkinson, 1993; Jenkinson et al, 1992; Stalker \& Harris, 1998).

We argue here that there is only so much that can be achieved by re-writing policy documents and vision statements, by changing the type and membership of meetings held in services, by redesigning the filing system, and by sending people to workshops outside of their immediate working environments. None of these expose the staff to an objective record of their own practices. Our basic argument can be simply put: if a staff member is to change their practice, then a good way to encourage the self-reflection that must be the first step to that change is to talk them through a video record of their day-to-day experience with residents (see Purcell, McConkey \& Morris, 2000 for this argument in respect to improving staff communication in services).

What video can capture.

Over the last two years, our research team has conducted an in-depth study of three residential services in the NHS (one health care and two social care), collecting ethnographic notes and video recordings of what actually goes on from day-to-day in 
the everyday lives of people with learning disabilities. Our findings, based on these notes and recordings, illustrate that disempowerment and dependence happen in the routine matters of people's lives. Power is exercised in the way people talk to each other, in what is and is not assumed, in what utterances are taken seriously and what are ignored, in the routines of residential provision, and in how conversations and meetings are directed, among others (Finlay, Walton \& Antaki, in press). Ironically, the recorded data show that even forums which are set up to promote service-user empowerment and inclusion can become sites for disempowerment depending on the way in which the interactions are structured (Jingree, Finlay \& Antaki, 2006; Antaki, Finlay, Sheridan, Jingree \& Walton, 2006; Antaki, Young \& Finlay, 2002).

This is not to blame the staff involved; in most cases they act with the best of intentions. It is simply that there are routine ways of doing things, and routine assumptions by which people operate, which are barely noticed yet which have important effects on the people whose lives exist within services (for examples, see Bradshaw, 2001; Markova, 1991; McConkey, Morris \& Purcell, 1999; McConkey, Purcell \& Morris, 1999). The method of analysis we favour, Conversation Analysis (CA), shows us that much of what goes on between people is so rapid and mundane that it goes 'under the radar' (for an account of CA see Hutchby and Wooffitt, 1998). But being unnoticed does not mean it is not important - when we look carefully at videos of life in residential care we can see how power and influence, dependence and independence are woven into people's talk and interactions with each other. For this reason, we believe that only limited results can be achieved through sending people to workshops to learn about and discuss person-centred approaches. Although this certainly help people understand the principles and what they might do to change, it can leave untouched all the behaviours that are so routine they are barely noticed 
Staff need to see, from a distance and in detail, what they actually do (in their own services) when they talk to people with learning disabilities, when they encourage (or not) participation, when they try and elicit a person's preferences, or when they respond to a complaint or suggestion from a person, for example. Video of real interactions is the medium of choice for this process, and although used in areas such as family therapy as part of reflective practice, it has surprisingly not made much of an impact in improving services for people with learning disabilities (although see Dobson, Upadhyaya \& Stanley, 2002; Embregts, 2002 a \& b; Nind \& Hewitt, 2001; Purcell et al, 2000 for notable exceptions). Given that communication and understanding is often a central issue, particularly in services for those with severe and multiple impairments, video records, set into their ethnographic background, offer the best available way to address what is currently done and how it can be improved; certainly they provide an immediate and detailed way by which people can observe and reflect upon their own individual and collective practices.

\section{Examples}

We shall provide a few examples from our study of two broad areas in which video can be useful in encouraging change in services:

\section{1) Changes in interactional style.}

Staff can become aware of aspects of their own behaviour that make it difficult for service-users to assert themselves. For example, we found that in an effort to check the understanding of the person from whom they were seeking an opinion, staff in one service would habitually rephrase questions several times in quick succession before an answer had been given. This made it difficult for the resident since they could not be sure which question they were supposed to be answering; 
often this led to no response being given. In other cases, we found that staff would often check the answers that residents gave, by repeating or subtly rephrasing the original question. Again, members of staff did this to make sure that the answer given by the resident really reflected their (the residents') needs or wishes. Unfortunately, this was often taken by the resident to indicate that their original answer was not acceptable, and they would then offer a different answer, further compounding staff uncertainty about what that individual really wanted. Another problem identified was staff eliciting views using questioning styles that encouraged residents to state their satisfaction rather than to voice their dissatisfaction or complaints (eg Everything ok? Are you happy?).

For residents who had limited verbal communication, watching the video revealed the use of subtle or slightly mistimed gestures and signs, understandable as expressions of preference, which routinely passed unnoticed by members of staff. A final example involved service-user meetings. Although set up as a forums within which people could speak for themselves, recordings showed staff facilitators engaging in a range of practices that determined who could speak at any particular time, what topics were appropriate for discussion and the decisions that were made. Although meetings are useful 'evidence' for inspectors that a home promotes empowerment, it was clear that other forums might be better for some residents to express their preferences.

\section{2) Changes in service structure and routine.}

Video records can also highlight how more general service routines and practice might change to provide more opportunities for resident participation and choice. When staff talked about why they did what they did on the videos, we found that they often held beliefs about what they were and were not allowed to do (based 
on ideas about health and safety guidelines, policy, rules or inspection requirements) that turned out to be wrong. For example, having viewed a routine monthly episode in which residents were weighed, as a check on their general health, and during which several residents made clear their resistance to being weighed in the face of repeated attempts by staff to persuade them, the staff group involved decided that monthly weighing for all residents was actually not necessary. In one home in which staff routinely made drinks for the residents, viewing a recording in which a staff member successfully supported the residents in making their own drinks showed other members of staff that, with assistance, the residents could do it themselves and that their fears over health and safety were unjustified. This video also revealed how the layout of the kitchen and the store cupboard were obstacles to the residents' participation, and possible future independence, and a number of changes were agreed upon. Finally, in the same home, a video of one man preparing food showed that, although he failed to do a particular task several times in a row (putting sprinkles on a pudding), with encouragement and support he was finally able to do it himself. Because he was not thought capable, other staff would normally not give him the opportunity to participate in cooking.

\section{Guidelines}

Using videos in staff development and service improvement has the potential to make real differences to services, and can add a useful tool to the armoury of those responsible for quality assurance in health and social care services. It is a very revealing way of carrying out a critical reflection on one's practice.

However, delicate preparation and strict procedures need to be followed to protect people's rights and dignity, and to ensure staff do not reject the process. The 
general procedure would involve a single service, for example a group home or an assessment centre (we shall use the example of residential services here). There are various possibilities for leading the process: it could be done with an independent facilitator, in conjunction with a self-advocacy group, or as a group-directed activity involving a small staff and client group. If it is to become a routine part of practice, the latter needs to become the model. Although the process could be led by a service manager, this might introduce other agendas, concerns and obligations into discussions which would interfere with the process. If a manager is involved, they would have to be extremely sensitive, non-judgemental, and have the trust of the other people involved in the process.

Careful attention needs to be paid to the issue of consent, both for the people living in the service and the staff who are likely to be involved. The procedures used for inviting people to participate in the recordings should be as rigorous as those for participation in a research project. This should include detailed and understandable information as to the uses of the recordings, and clear explanations about the ability of people to decline and to withdraw at any stage without the fear of negative consequences. With the appropriate consents in place, recordings would be made of a number of routine episodes (e.g. residents' meetings where staff are present; teaching sessions; menu planning; food preparation and choice; negotiation over outings, parties, house maintenance; discussions with residents around their preferences for activities, holidays etc). Once these are collected, some episodes would be identified which appeared to go well (in terms of respecting residents' preferences, encouraging independence etc) and some episodes which were problematic. The selection of the episodes would very much depend on the agenda of the service and the staff group. A workshop would then be held in which these episodes would be viewed and 
discussed. It is important that each clip is viewed more than once, with a discussion after each viewing, since the nature of interaction is such that new aspects usually become apparent only on repeated inspection of the recordings (Dobson et al, 2002). The procedure would therefore be: first viewing - discussion - second viewing discussion - until the group felt it was time to move to the next clip. We have found that as long as there is a 'no blame' policy to the workshops, staff find this an interesting and engaging process, and people often see things they did not know they did ('Do I really do that?'). Suggestions for how things might be done differently can easily be generated in such contexts, and indeed the meetings should end by enumerating the changes that the service and individual workers might make to promote choice and independence.

A number of safe-guards need to be put in place before video work can be done:

1) An initial meeting should be held with staff and those living in the service where it is decided what and who shall be videoed. Since staff may be reluctant to be recorded, managers and senior staff could set an example by volunteering themselves in the first case. There should be no compulsion or pressure over who is recorded, and there should be no consequences for people who do not wish it.

2) Strict consent and confidentiality guidelines should be followed. Videos should not be passed on to management and should not be used for evaluation purposes. At the end of the session, unless the members of staff involved agree to retain and use the videos again, all tapes should be deleted in front of the participants.

3) People with learning disabilities who appear in the video should be consulted seriously and carefully about whether they wish to be filmed, and all ethical and confidentiality procedures followed. In situations in which people are unable to give 
consent themselves, the procedures for participation on the basis of assent should be followed. In these deliberations, it should be remembered that this video work should lead to direct benefits for service-users. Again, there should be no compulsion to participate.

4) Managers and supervisors should approach the viewing sessions carefully. If staff are criticized for what they do on tape, discussions will break down and others will not agree to be filmed. Except for cases of abusive practice, a 'no blame' approach should be taken at all times. Here it is useful to remember that staff have to fulfil a number of service agendas which often conflict (e.g. health and safety versus choice) and they operate within structures and routines which appear set in stone (even if they are often not). Many interactions in residential services involve a difficult balancing act regarding the interests and expectations of different stake-holders (management, different residents, other workers, families), conflicting agendas of care, and communication difficulties between staff and service-users. As such, individuals should be assured that when they find situations difficult others do also, and it is not them but the situation which is the focus of the discussion.

5) Workshops should focus equally on what works well as where problems arise. That is, clips selected should include good practice as well as difficulties. Members of staff often hold the solutions to problems or have ideas of how things could be done differently. New ways of doing things and new opportunities for the residents can be identified and agreed upon on the basis of seeing one staff member do something that others don't do, either because they believe it can't work or that there are obstacles to doing it.

\section{Conclusion}


This is a manifesto for the use of video as a way of promoting person-centred approaches in residential care. It is based on the observation that much disempowerment occurs in the mundane, barely noticed details of life in services, and that staff can only engage fully with this by watching what they and their co-workers do from a distance. Following the arguments of Purcell et al (2000), we believe that services will only become truly person-centred when this level of attention is paid to the details of interaction between staff and people with learning disabilities. Given that many interactions between staff and people with learning difficulties proceed on the basis of unequal institutional power and differences in communicative abilities and understanding, it is surprising that this is not already standard practice. Video is routinely used in other areas in which interactional details are crucial such as family therapy, and it should be used in services for people with learning disabilities as a central tool of reflective practice.

\section{Acknowledgements}

The research reported here was facilitated by grant number Res-148-25-0002 from the United Kingdom ESRC. Many thanks to those residents and staff involved in the research, as well as the NHS Trust which hosted the research.

\section{References}

Antaki, C., Finlay, W.M.L., Sheridan, E., Jingree, T. \& Walton, C. (2006). Producing decisions in service-user groups for people with an intellectual disability: two contrasting facilitator styles. Mental Retardation, 44, 322-343. 
Antaki, C., Young, N. \& Finlay, W.M.L. (2002). Shaping clients' answers:

Departures from neutrality in care-staff interviews with people with a learning disability. Disability \& Society, 17 (4), 435-455.

Beamer, S. \& Brookes, M. (2001) Making decisions: best practice and new ideas for supporting people with high support needs to make decisions. London: VIA

Bradshaw, J. (2001) Complexity of staff communication and reported level of understanding skills in adults with intellectual disability. Journal of Intellectual Disability Research, 45, 233-243

Department of Health (United Kingdom). (2001). Valuing people. London: Her Majesty's Stationery Office.

Dobson, S., Upadhyaya, S. \& Stanley, B. (2002) Using an interdisciplinary approach to training to develop the quality of communication with adults with profound learning disabilities by care staff. International Journal of Language and Communication Disorders, 37, 41-57

Dowson, S. (1997). Empowerment within services: a comfortable delusion. In P.

Ramcharan, G. Roberts, G. Grant \& J. Borland (eds) Empowerment in everyday life: learning disability. London: Jessica Kingsley

Edge, J. (2001) Who's in control?: decision-making by people with learning difficulties who have high support needs. London: Values Into Action. 
Embregts, P.J.C.M. (2002a) Effect of resident and direct-care staff training on responding during social interactions. Research in Developmental Disabilities, 23, $353-366$

Embregts, P.J.C.M. (2002b) Effects of video feedback on social behaviour of young people with mild intellectual disability and staff responses. International Journal of Disability, Development and Education, 49, 105-116

Finlay, W.M.L., Walton, C. \& Antaki, C. (in press). Promoting choice and control in residential services for people with learning disabilities. Disability \& Society.

Harris, J. (2003) Time to make up your mind: why choosing is difficult. British Journal of Learning Disabilities, 31, 3-8.

HM Government (2005) The Government's annual report on Learning Disability, 2005. Valuing People: making things better. TSO: Norwich

Hutchby, I and Wooffitt, R (1998) Conversation Analysis. Oxford: Polity Press.

Jenkinson, J.C. (1993) Who shall decide? The relevance of theory and research to decision-making by people with an intellectual disability. Disability, Handicap and Society, $8,361-375$

Jenkinson, J., Copeland, C., Drivas, B., Scoon, H., Yap, M.L. (1992) Decisionmaking by community residents with an intellectual disability. Australia and New Zealand Journal of Developmental Disabilities, 18, 1-8. 
Jingree, T., Finlay, W.M.L. \& Antaki, C. (2006). Empowering words, disempowering actions. Journal of Intellectual Disability Research, 50, 212-226

Marková, I. (1991) Asymmetries in group conversations between a tutor and people with learning difficulties. In Marková, I and Foppa, K. (Eds) Asymmetries in Dialogue. Hemel Hempstead, Harvester Wheatsheaf.

McConkey, R.M., Morris, I. \& Purcell, M. (1999) Communications between staff and adults with intellectual disabilities in naturally occurring settings. Journal of Intellectual Disability Research, 43, 194-205

McConkey, R.M., Purcell, M. \& Morris, I. (1999) Staff perceptions of communication with a partner who is intellectually disabled. Journal of Applied Research in Intellectual Disabilities, $12,204-210$

Nind, M. \& Hewett, D. (2001) A practical guide to intensive interaction. Kidderminster: BILD Publications.

Purcell, M., McConkey, R. \& Morris, I. (2000) Staff communication with people with intellectual disabilities: the impact of a work-based training programme. International Journal of Language and Communication Disorders, 35, 147-158

Stalker, K. \& Harris, P. (1998) The exercise of choice by adults with intellectual disabilities: a literature review. Journal of Applied Research in Intellectual Disabilities, $11,60-76$ 
